\title{
Primary gastric choriocarcinoma: two case reports and a pooled analysis of 53 cases
}

\author{
Akihiro Kobayashi ${ }^{1,3}$, Takahiro Hasebe ${ }^{1}$, Yasushi Endo ${ }^{1}$, Satoshi Sasaki ${ }^{2}$, Masaru Konishi ${ }^{3}$, \\ Masanori Sugito ${ }^{3}$, Taira Kinoshita ${ }^{3}$, Norio Saito ${ }^{3}$, and Atsushi Ochiai ${ }^{1}$ \\ ${ }^{1}$ Pathology Division, National Cancer Center Research Institute East, 6-5-1 Kashiwanoha, Kashiwa, Chiba 277-8577, Japan \\ ${ }^{2}$ Epidemiology and Biostatistics Division, National Cancer Center Research Institute East, Kashiwa, Japan \\ ${ }^{3}$ Department of Surgery, National Cancer Center Hospital East, Kashiwanoha, Kashiwa, Japan
}

\begin{abstract}
Primary gastric choriocarcinoma (PGC) is a rare tumor. In total, approximately 140 cases of PGC have been reported in the international medical literature. However, the clinical behavior, tumor characteristics, and prognostic parameters of PGC have not been clearly described. We conducted a pooled analysis to clarify the tumor characteristics and prognostic parameters in 53 patients with PGCs, including 2 patients treated at our hospital. The following variables were examined as potential prognostic factors: (1) sex, (2) age, (3) depth of invasion, (4) size, (5) histology, (6) nodal metastasis, (7) distant lymph node metastasis, (8) synchronous liver metastasis, (9) residual tumor, and (10) chemotherapy (not given or given). Univariate and multivariate analyses showed that the presence of residual tumor and synchronous liver metastasis and the absence of chemotherapy were significantly associated with an increased hazard rate (HR) of short overall survival (OS). Pooled analysis, including the two patients with PGC treated at our facility, demonstrated that the presence of a curative operation and chemotherapy, and the absence of synchronous liver metastasis were the strongest indicators of a favorable clinical course in patients with PGC.
\end{abstract}

Key words Choriocarcinoma $\cdot$ Stomach $\cdot$ Prognosis

\section{Introduction}

Primary gastric choriocarcinoma (PGC) is a rare tumor that is reported to account for approximately $0.08 \%$ of all gastric cancers [1]. Most PGCs have been reported to possess an adenocarcinoma component of variable extent, and pure PGC is especially rare [2-4].

In the English-language medical literature, approximately 30 PGC cases have been reported to date. While the clinicopathological characteristics or prognostic pa-

Offprint requests to: A. Ochiai

Received: November 25, 2004 / Accepted: April 1, 2005 rameters of PGCs were described in some of these reports, most of the conclusions were unreliable because of the small number of PGC cases analyzed.

In the present study, we conducted a pooled analysis of 53 PGC cases, including 2 patients treated at the National Cancer Center Hospital East (NCCHE), to clarify the tumor characteristics and prognostic parameters of patients with PGC.

\section{Case reports}

Case 1

A 74-year-old man complaining of loss of appetite and loss of body weight, for 9 months, visited the NCCHE. Laboratory data showed anemia (RBC, $369 \times 10^{4} / \mathrm{mm}^{3}$; hemoglobin [Hb], $8.4 \mathrm{~g} / \mathrm{dl}$; hematocrit [Hct], 28.5\%), hypoalbuminemia (serum albumin, $3.0 \mathrm{~g} / \mathrm{dl}$ ), and high serum carcinoembryonic antigen (CEA; $31.2 \mathrm{ng} / \mathrm{ml}$; normal, $0-5 \mathrm{ng} / \mathrm{ml}$ ).

A gastrointestinal X-ray examination revealed an ulcerated lesion with a distinct elevation occupying the lower third of the stomach and invading the duodenum. The lesion was endoscopically diagnosed as a gastric cancer, and a biopsy specimen taken from its margin revealed well-differentiated tubular adenocarcinoma. A computed tomography (CT) scan and echography showed no evidence of liver metastasis at this time.

A radical subtotal Billroth II gastrectomy with lymph node dissection, omentectomy, and partial resection of the pancreatic head was performed. Macroscopically, no signs of liver metastasis or retroperitoneal invasion were observed.

The resected tumor was $11.5 \times 8.5 \times 5.0 \mathrm{~cm}$ in size. The tumor had extended to the serosa (T3) and had directly invaded the duodenum. A metastasis was found in one of the supragastric lymph nodes (N1). Grossly, the tumor was fungating (Fig. 1). Histologically, the tumor 


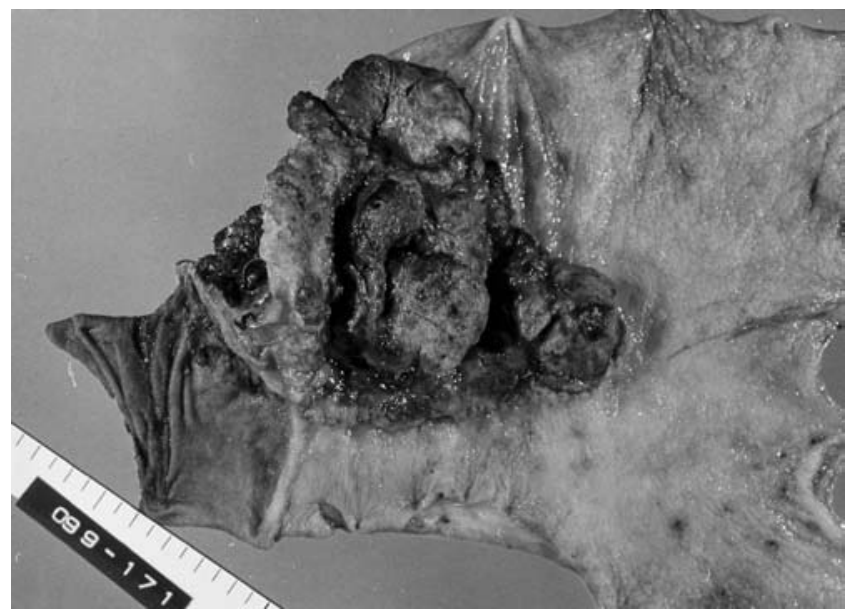

Fig. 1. Photograph of the tumor shows a large ulcerative tumor with a hemorrhagic central protrusion had two components. The first component was a moderately differentiated tubular adenocarcinoma, accounting for approximately $80 \%$ of the entire tumor (Fig. $2 \mathrm{~A})$. The remaining $20 \%$ of the tumor was a pleomorphic carcinoma with several syncytiotrophoblastic giant cells and hemorrhage; the histological features of this component were very suggestive of a choriocarcinoma (Fig. 2B,C). A gradual transition between the two components was observed, and the second component consisted mainly of a protruding lesion. The single nodal metastasis was composed only of tubular adenocarcinoma cells. Positive immunohistochemical staining for the beta subunit of human chorionic gonadotropin (HCG; rabbit polyclonal antibody for HCG, diluted 1:200; Dako, Copenhagen, Denmark) was observed only in the choriocarcinoma-like component (Fig. 2D). Thus, this component was diagnosed as a choriocarci-
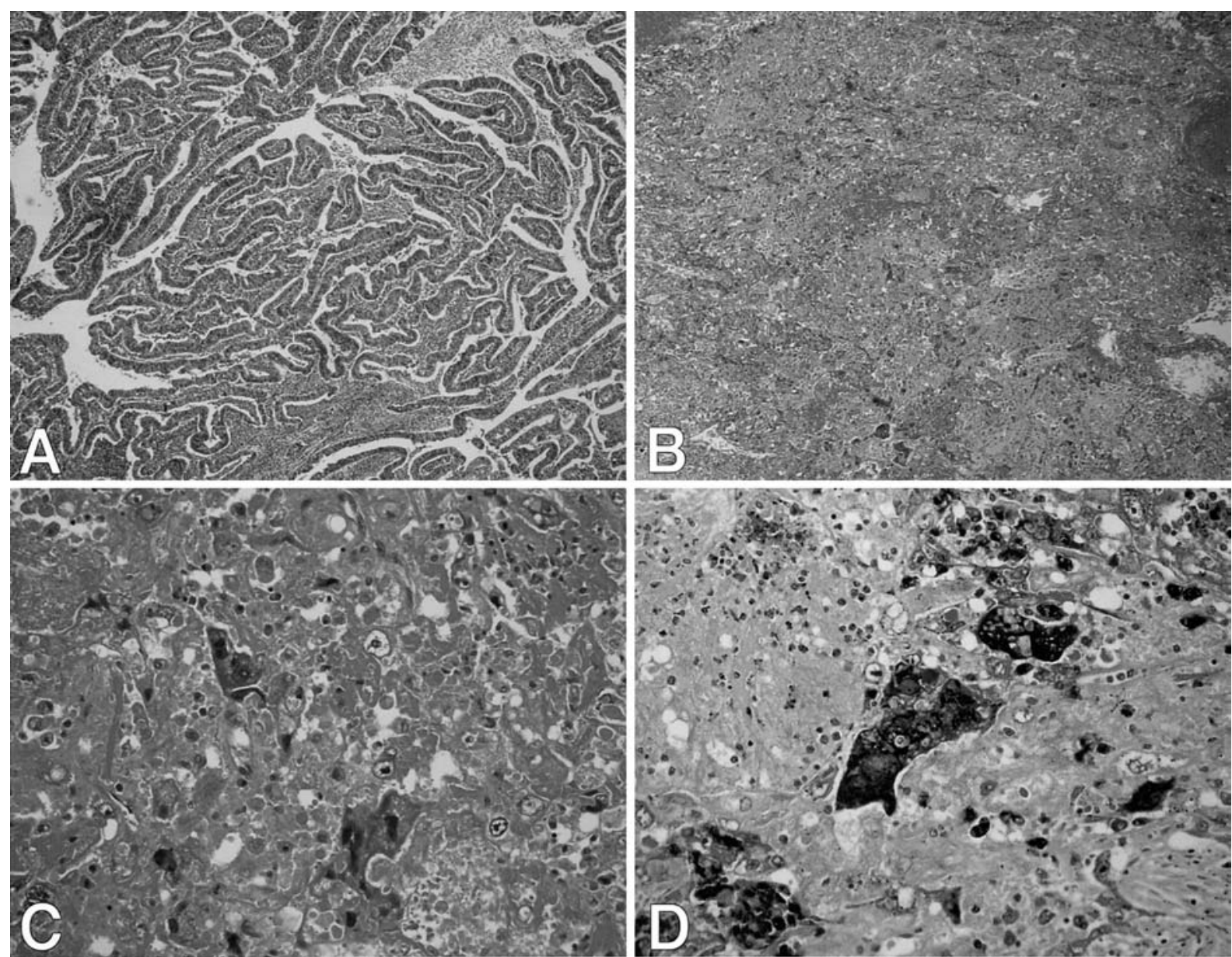

Fig. 2A-D. Photomicrographs of the surgical specimen. A Adenocarcinomatous component. B Choriocarcinomatous component, consisting of syncytiotrophoblasts and cytotrophoblasts with marked hemorrhage. C Choriocarcinomatous component with syncytiotrophoblastic giant cells. D Immunohistochemical staining for the beta subunit of human chorionic gonadotropin $(\beta$ $\mathrm{HCG})$ in the choriocarcinomatous component. A and B H\&E, $\times 85 ; \mathbf{C ~ H} \& \mathrm{E}, \times 340 ; \mathbf{D} \times 340$ 


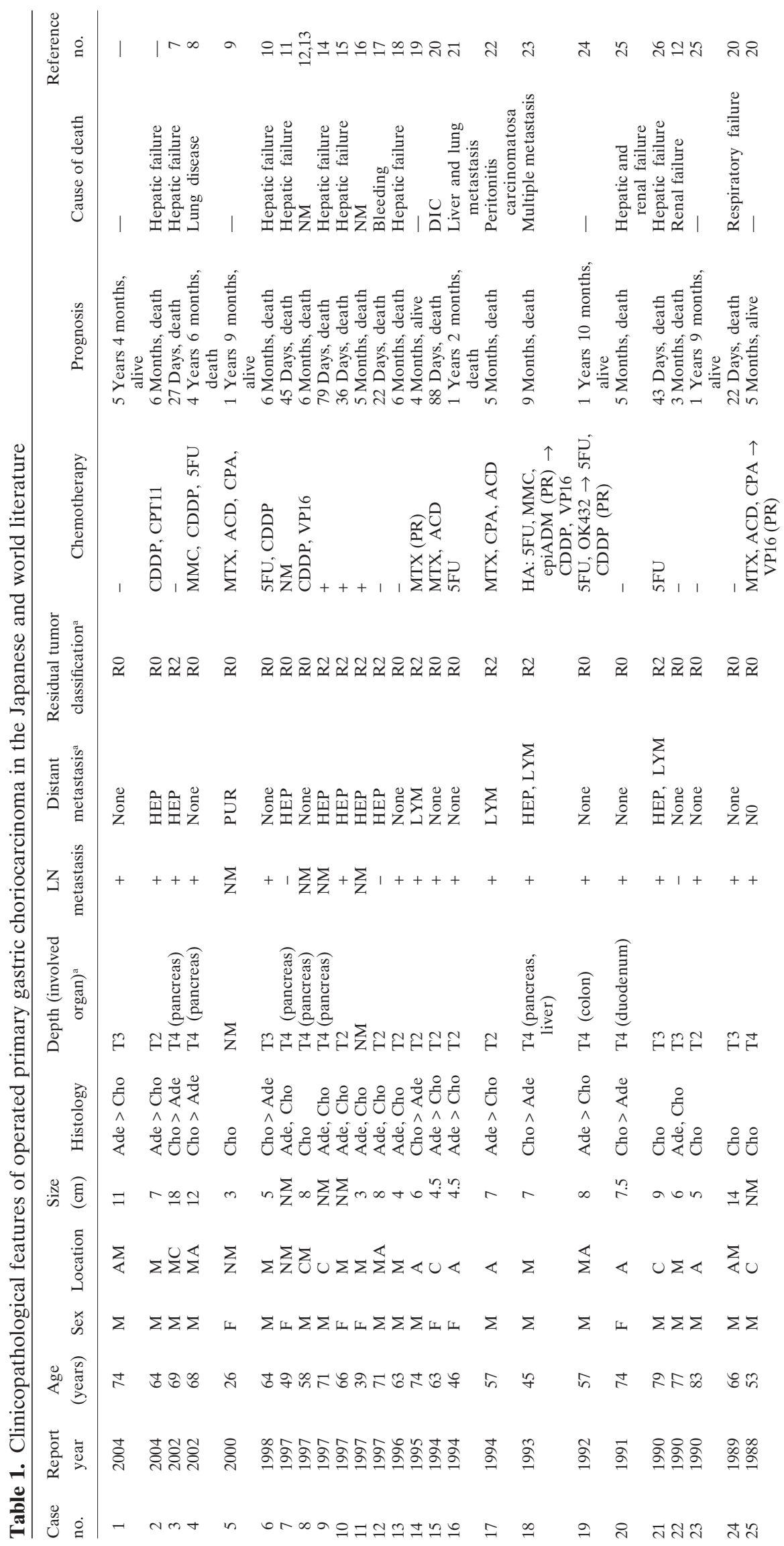




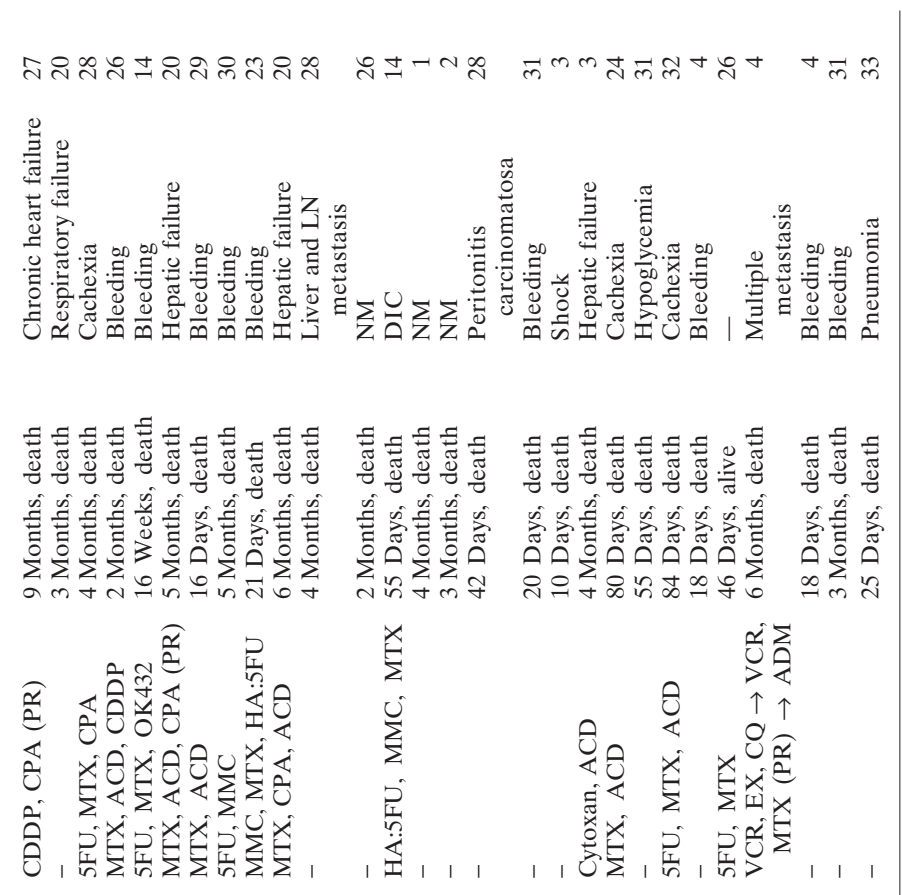

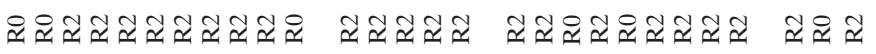

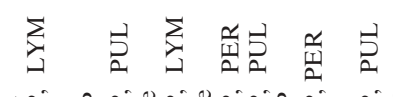

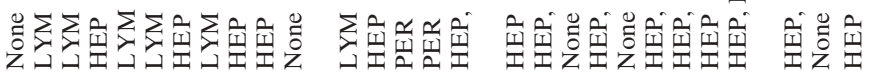

$+++\frac{\bar{\Sigma}}{\mathrm{Z}}++\frac{\bar{\Sigma}}{\mathrm{Z}}++++++++++\bar{\Sigma}_{\mathrm{Z}} 1+1+++++1+$

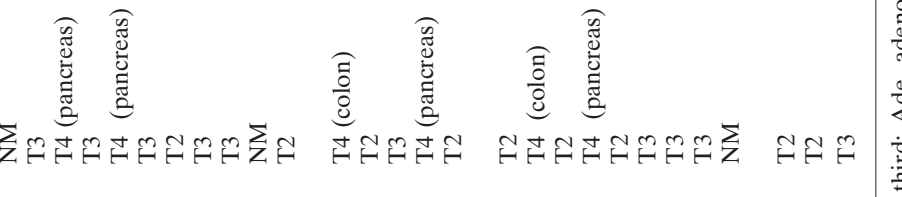

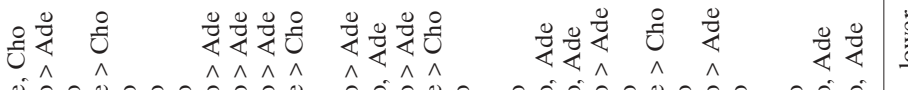

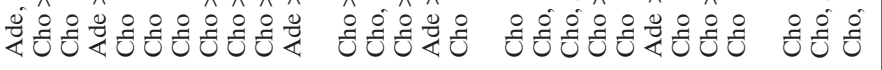

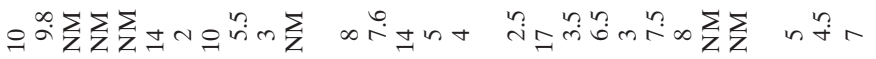

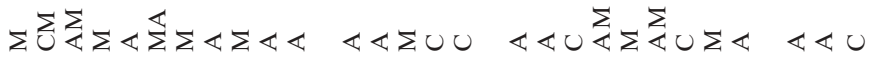

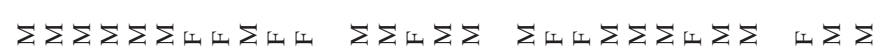

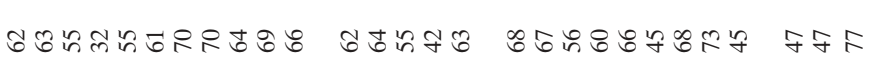

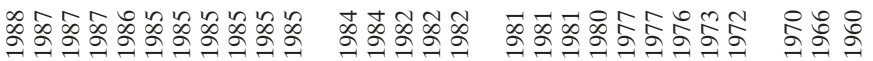

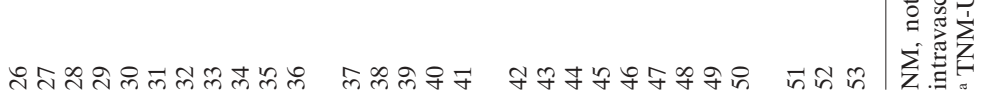


noma. Based on these findings, the tumor was diagnosed as a moderately differentiated tubular adenocarcinoma with a choriocarcinoma component.

In case 1 , the preoperative, 2 -week postoperative, and 6-month postoperative HCG levels were 1055, 44.7, and less than $0.5 \mathrm{mIU} / \mathrm{ml}$, respectively (normal range, $<0.5 \mathrm{mIU} / \mathrm{ml}$ ). The patient's postoperative course was uneventful, and he remains recurrence-free 64 months after the operation.

\section{Case 2}

A 64-year-old man visited our hospital for a routine medical examination. Laboratory data showed erythema $\left(\mathrm{RBC}, 700 \times 10^{4} / \mathrm{mm}^{3} ; \mathrm{Hb}, 16.0 \mathrm{~g} / \mathrm{dl} ; \mathrm{Hct}\right.$, $51.2 \%$; WBC, $17000 / \mathrm{mm}^{3}$; platelets [Plt], $54 \times 10^{4} / \mathrm{mm}^{3}$ ) and a high serum alpha-fetoprotein (AFP) value $(2307.2 \mathrm{ng} / \mathrm{ml}$; normal, $<9.5 \mathrm{ng} / \mathrm{ml})$. Neither gynecomastia nor abdominal abnormalities were recognized. A chest X-ray showed no abnormal shadows.

A gastrointestinal X-ray examination revealed an ulcerated mass occupying the upper third of the stomach. The mass was endoscopically diagnosed as a gastric cancer, and a biopsy specimen taken from an elevated lesion at the tumor margin revealed a moderately differentiated tubular adenocarcinoma. A CT scan showed regional lymph node swelling and metastases in the lateral segment of the liver.

A radical total gastrectomy, with lymph node dissection, splenectomy, and partial hepatic resection was performed. At the time of the operation, a macroscopic examination showed no metastatic tumors in the retroperitoneal area.

The resected tumor was $7.0 \times 7.0 \mathrm{~cm}$ in size. The tumor had extended to the subserosa (T2), and six regional lymph node metastases were identified (N1). Grossly, the tumor showed macroscopic features consistent with a type-3 lesion. Histologically, the tumor was composed of a well-differentiated tubular adenocarcinoma and a carcinoma with pleomorphic features. The former component accounted for approximately $90 \%$ of the entire tumor. The latter component contained syncytiotrophoblastic giant cells and hemorrhage; the histological features of this component were consistent with a choriocarcinoma. The hemorrhagic component of this tumor was composed only of choriocarcinoma-like tumor cells. All six nodal metastases were composed of tubular adenocarcinoma cells. Because positive immunohistochemical staining for the beta subunit of HCG was observed only in the choriocarcinoma-like component, this component was diagnosed as a choriocarcinoma. Based on these findings, the tumor was diagnosed as a well-differentiated tubular adenocarcinoma with a choriocarcinoma component.
In case 2 , the preoperative and 2 -week postoperative HCG levels were 246.9 and $2.3 \mathrm{mIU} / \mathrm{ml}$, respectively. The patient's immediate postoperative course was uneventful, and he was treated with combination chemotherapy consisting of cisplatin (CDDP) and carboplatin (CPT-11) [5,6], as for AFP-producing gastric cancer. However, multiple liver metastases were detected 1 month after the operation, and his serum AFP level increased to $2307.2 \mathrm{ng} / \mathrm{ml}$. The patient died 6 months after the operation.

\section{Reported PGC cases and pooled analysis}

\section{Cases and methods}

We retrospectively collected all the reported PGC cases and chose all operated cases (curative or noncurative) with a clear postoperative prognosis. Fifty-three cases of PGC have been documented previously [1-4,7-33] including the 2 cases reported here. All cases were classified according to the pTNM classification [34]. Measurement of the overall survival (OS) periods began at the time of surgery. Death due to gastric cancer was the only endpoint considered for the purpose of this study. The OS curves were drawn using the Kaplan-Meier method, and differences between the curves were compared using log-rank tests. The Cox proportional hazards regression model was used to estimate the multivariate hazard risk (HR) of tumor death (with a $95 \%$ confidence interval $[\mathrm{CI}]$ ). The following variables were examined as potential prognostic factors: (1) sex, (2) age ( $<64$ years or $\geqq 64$ years), (3) depth of invasion (T2 or T3, T4), (4) size $(<7 \mathrm{~cm}$ or $\geqq 7 \mathrm{~cm}),(5)$ histology ([adenocarcinoma $>$ choriocarcinoma] or [choriocarcinoma $>$ adenocarcinoma]), (6) regional lymph node metastasis (negative or positive), (7) distant lymph node metastasis (negative or positive), (8) synchronous liver metastasis (absent or present), (9) residual tumor after operation (absent or present), and (10) chemotherapy (not given or given). The cutoff values for size and age in this study were the median values for the patients in the pooled analysis. The variables associated with a significant increase in the HR of tumor death in the univariate analysis were entered into the multiple regression analysis, using the step-down method.

\section{Results of pooled analysis}

Clinicopathological and follow-up data from the patients are presented in Table 1. Thirty-seven men and 16 women were included in the analysis $(\mathrm{M} / \mathrm{F}$ ratio, $2.3: 1)$. The mean age of the men was 62.4 years (median, 63 years; range, 32-83 years) and that of the women was 54.8 years (median, 63 years; range, $26-74$ years). In the 
51 previously reported patients, the PGC was most frequently located in the lower third of the stomach $(41 \%$; $21 / 51)$, followed by the middle third $(37 \% ; 19 / 51)$ and the upper third $(22 \% ; 11 / 51)$; the location frequently coincided with the location of the gastric adenocarcinoma [4]. The tumor sizes ranged from 2 to $18 \mathrm{~cm}$ (mean, $7.0 \mathrm{~cm}$ ) in diameter, and nearly all the tumors were accompanied by macroscopic hemorrhage or necrosis. Thirty-seven patients $(70 \%)$ had PGCs that exhibited an adenocarcinoma component. Most patients with PGC had metastatic lesions at the time of operation. The rates of lymph node, liver, peritoneal, and lung metastases were $87 \%$ (40/46), 45\% (24/53), 23\% $(12 / 53)$, and $8 \%(4 / 53)$, respectively. Denominators indicate numbers of patients for whom the parameter was mentioned. The percentages of patients with a choriocarcinoma component in the lymph node and liver were $63 \%(19 / 30)$ and $96 \%(24 / 25)$, respectively. All patients with PGC had invasion beyond the muscularis propria (T2-T4). Postoperatively, residual tumor was found in 31 of the 53 patients $(58 \%)$, because of distant metasta- sis. The most frequent cause of death was hepatic failure because of tumor metastasis $(29 \% ; 12 / 41)$, followed by the bleeding of primary or metastatic tumors $(24 \% ; 10 /$ $41)$. Only $8 \%(4 / 53)$ of the PGC cases were diagnosed correctly by endoscopic biopsy.

On univariate and multivariate analyses, the presence of synchronous liver metastasis, the presence of residual tumor after operation, and the absence of chemotherapy were significantly associated with a short OS (Table 2). On the univariate analysis, the other parameters showed no significant association with a short OS. The OS curves are shown in Fig. 3A-C. Of the 53 patients, 10 died less than 1 month postoperatively (19\%; Table 1).

\section{Discussion}

Davidsohn [35] first described PGC in 1905, and approximately 140 cases have been reported in the international medical literature to date. However, most of

Table 2. Univariate and multivariate analyses for overall survival (OS) periods (days) in PGC patients

\begin{tabular}{|c|c|c|c|c|c|c|}
\hline \multirow[b]{2}{*}{ Parameter } & \multicolumn{4}{|c|}{ Univariate } & \multicolumn{2}{|c|}{ Multivariate } \\
\hline & No. & $\operatorname{Rec}(\%)$ & $P$ value ${ }^{a}$ & HR & $95 \%$ CI & Cox $P$ value \\
\hline Chemotherapy & 52 & & & & & \\
\hline Given & 31 & $24(77)$ & & & 1.0 & Referent \\
\hline Not given & 21 & $18(86)$ & 0.037 & 4.4 & $2.4-9.4$ & $<0.001$ \\
\hline Residual tumor after & & & & & & \\
\hline operation & 53 & & & & & \\
\hline Absent & 22 & $14(64)$ & & & 1.0 & Referent \\
\hline Present & 31 & $29(94)$ & $<0.001$ & 3.3 & $1.4-7.8$ & 0.008 \\
\hline Synchronous liver metastasis & 53 & & & & & \\
\hline Absent & 29 & $20(69)$ & & & 1.0 & Referent \\
\hline Present & 24 & $23(96)$ & $<0.001$ & 3.0 & $1.3-7.1$ & 0.013 \\
\hline LN metastasis & 46 & & & & & \\
\hline Negative & 6 & $5(83)$ & & & & \\
\hline Positive & 40 & $32(80)$ & 0.162 & & & \\
\hline Age & 53 & & & & & \\
\hline High ( $\geqq 64$ years) & 26 & $20(77)$ & & & & \\
\hline Low ( $<64$ years) & 27 & $23(85)$ & 0.394 & & & \\
\hline Histology & 42 & & & & & \\
\hline Chorio $>$ adeno & 32 & $25(78)$ & & & & \\
\hline Adeno $>$ chorio & 10 & $8(80)$ & 0.411 & & & \\
\hline Sex & 53 & & & & & \\
\hline Male & 36 & $27(75)$ & & & & \\
\hline Female & 17 & $16(94)$ & 0.425 & & & \\
\hline Distant LN metastasis & 53 & & & & & \\
\hline Negative & 41 & $32(78)$ & & & & \\
\hline Positive & 12 & $11(92)$ & 0.499 & & & \\
\hline Depth & 48 & & & & & \\
\hline $\mathrm{T} 2$ & 18 & $15(83)$ & & & & \\
\hline $\mathrm{T} 3,4$ & 30 & $25(83)$ & 0.888 & & & \\
\hline Size & 43 & & & & & \\
\hline Small $(<7 \mathrm{~cm})$ & 20 & $16(80)$ & & & & \\
\hline Large $(\geqq 7 \mathrm{~cm})$ & 23 & $19(83)$ & 0.968 & & & \\
\hline
\end{tabular}

Rec, recurrence; HR, hazard ratio; CI, confidence interval; LN, lymph node; chorio, choriocarcinoma; adeno, adenocarcinoma

a $P$ values are based on the log-rank test 

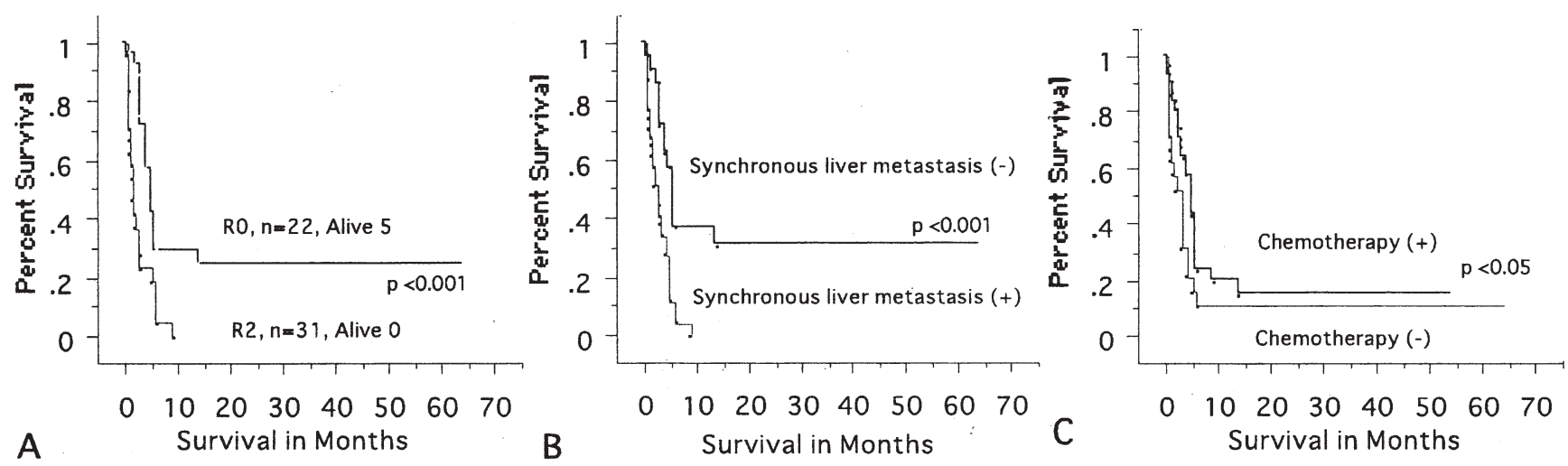

Fig. 3A-C. Overall survival curves of patients with primary gastric choriocarcinoma (PGC). A Residual tumor after operation (absent or present); $P<0.001$. B Synchronous liver metastasis (absent or present); $P<0.001$. C Chemotherapy (given or not given); $P<0.05$

the cases were presented as single case reports or small series, and no studies have precisely examined the prognostic parameters for patients with PGCs. The clinicopathology and prognostic factors of PGCs also have yet to be elucidated. This prompted us to perform a pooled analysis of PGC cases to identify the biological characteristics of PGCs and establish prognostic clinicopathological parameters.

Several studies have indicated that the pathogenesis of PGC can be explained as the dedifferentiation of malignant adenocarcinoma tissue to the level of the embryonal ectoderm, retaining the ability to form trophoblasts [20,36]. Liu et al. [37] reported, with a comparative genomic hybridization and fluorescence in situ hybridization study, that PGC genetically possessed characteristics of both adenocarcinoma and gestational choriocarcinoma. In fact, the clinical features of gastric choriocarcinoma are similar to those of gastric adenocarcinoma; the mean age, male-female ratio, and tumor location all parallel those of primary gastric adenocarcinoma [27]. In the present two patients, the PGCs were accompanied by adenocarcinoma and exhibited a gradual transition from adenocarcinoma to choriocarcinoma components. These observations strongly suggest that the PGCs in the present patients originated from pre-existing gastric adenocarcinomas.

PGC is often diagnosed as adenocarcinoma because of the coexistence of adenocarcinoma and choriocarcinoma. That is why our patients were preoperatively diagnosed as having adenocarcinoma from endoscopic biopsy specimens. Only $8 \%$ (4/53) of the PGC cases were diagnosed correctly by biopsy.

Using univariate and multivariate analyses, our results demonstrated that synchronous liver metastasis, residual tumor after surgery, and the absence of chemotherapy were significant prognostic parameters of a short OS. One of the main characteristics of the PGC patients was early death after operation because of hepatic failure, brought on by tumor metastasis, and bleeding of the primary or metastatic tumors. Of the ten patients who died within 1 month after operation, nine (90\%) had synchronous liver metastasis. In the present report, case 2 died of liver metastasis in spite of receiving a curative operation and chemotherapy. The presence of synchronous liver metastasis at the time of operation may represent an advanced metastatic state and may be associated with a poor clinical course in PGC patients. We suggest that a palliative gastrectomy should never be performed in such patients, as it is likely that the patients would die soon after such a procedure. Regional and distant lymph node metastases, which are potent prognostic factors for many tumors, were not significant prognostic parameters in the present study. Therefore, PGCs with a high metastatic potential, especially to the liver, may have the highest malignant potential among PGCs with tumor metastasis. Our case 1 has survived for 5 years and 4 months since receiving a curative operation. There is no established regimen of chemotherapy for PGC. Based on these clinicopathological findings, we speculated that a combination of $\mathrm{R} 0$ resection and adequate chemotherapy may contribute to the long-term survival of PGC patients.

The present study suggests that PGC is a highly aggressive tumor that is often associated with liver metastasis. Curative resection, appropriate chemotherapy, and the absence of synchronous liver metastasis are favorable prognostic factors for patients with PGC.

\section{References}

1. Umigami M, Hirota E, Itabashi M, Kodama T, Onuki K, Kitaoka $\mathrm{H}$, et al. Three cases of primary gastric chorioepithelioma (in 
Japanese). Gan No Rinsho (J Jpn Cancer Clinics) 1982;28:20410.

2. Mori H, Soeda O, Kamano T, Tsunekawa K, Ueda N, Yoshida A, et al. Choriocarcinomatous change with immunocytochemically HCG-positive cells in the gastric carcinoma of the males. Virchows Arch A Pathol Anat Histol 1982;396:141-53.

3. Saigo PE, Rosen PP, Brigati DJ, Turnbull AD, Sternberg SS. Primary gastric choriocarcinoma. An immunohistochemical study. Am J Surg 1981;5:333-42.

4. Jindrak K, Bochetto JF, Alpert LI. Primary gastric choriocarcinoma: case report with review of world literature. Hum Pathol 1976;7:595-604.

5. Boku N, Ohtsu A, Shimada Y, Shirao K, Seki S, Saito H, et al. Phase II study of a combination of irinotecan and cisplatin against metastatic gastric cancer. J Clin Oncol 1999;17:319-23.

6. Asami T, Kokawa A, Sugimori K, Tomita N, Shirato K, Morimoto M, et al. A case of AFP-producing gastric cancer with multiple liver metastases responding to CPT-11 and cisplatin combination chemotherapy. Gan To Kagaku Ryoho (Jpn J Cancer Chemother) 2002;29:1985-8.

7. Satake Y, Horimi T, Shima Y, Hamada M, Okabayashi T, Iwata $\mathrm{J}$, et al. A resected case of primary gastric choriocarcinoma (in Japanese). Nippon Shokakibyou Gakkai Zasshi (Jpn J Gastroenterol) 2002;99:1460-65.

8. Noguchi T, Takeno S, Sato T, Takahashi Y, Uchida Y, Yokoyama S. A patient with primary gastric choriocarcinoma who received a correct preoperative diagnosis and achieved prolonged survival. Gastric Cancer 2002;5:112-7.

9. Bayhan G, Yaldiz M, Yalinkaya A, Kilinc N, Gul T, Erden AC. Primary gastric choriocarcinoma: case report. Eur J Gynaecol Oncol 2000;21:316-7.

10. Nakao A, Sakagami K, Uda M, Mitsuoka S, Yamashita N, Ito H. Gastric carcinoma with predomonant choriocarcinomatous component. Int J Clin Oncol 1998;3:403-5.

11. Maruyama M, Kudo T, Kuwahara H, Takamatsu T, Sugano N, Ebuchi M. A case of gastric cancer containing choriocarcinoma and yolk sac tumor (in Japanese). Nippon Shokaki Shudan Kenshin (J Gastroenterol Mass Survery) 1997;35:616.

12. Kaneko T, Mochizuki M, Hakozaki H, Igari S. Imprint cytology of primary gastric choriocarcinoma. A case report (in Japanese with English abstract). J Jpn Soc Clin Cytol 1997;36:531-6.

13. Sato K, Watanabe O, Anzai K, Sano Z, Hiroishi K, Nakayama K, et al. Primary choriocarcinoma of the stomach (in Japanese with English abstract). Shokaki Naishikyo (Endoscopia Digestiva) 1995; 7:1289-96.

14. Tamada H. A case of primary gastric choriocarcinoma (in Japanese). Jpn J Gastroenterol Surg 1997;30:1622.

15. Ushida T, Morozumi K, Shibata S, Ikeda Y. A case of primary gastric choriocarcinoma (in Japanese). Jpn J Gastroenterol Surg 1997;30:1619.

16. Inomata $\mathrm{Y}$, Tadaoka $\mathrm{N}$, Yoshinaga $\mathrm{K}$, et al. Two cases of primary gastric choriocarcinoma and squamous cell carcinoma of the stomach (in Japanese). Nippon Shokaki Shudan Kenshin (J Gastroenterol Mass Survery) 1997;35:615.

17. Jan YJ, Chen JT, Ho WL, Wu CC, Yeh DC. Primary coexistent adenocarcinoma and choriocarcinoma of the stomach. A case report and review of the literature. J Clin Gastroenterol 1997;25: $550-4$.

18. Uda M, Sakaue K, Nakao A, Mitsuoka S. A case of primary gastric choriocarcinoma (in Japanese). Niseki Igaku (Jpn Red Cross Med J) 1996;48:115.

19. Kinoshita H, Sasaki M, Onishi H, Nishino E. A case report of primary gastric choriocarcinoma (in Japanese with English abstract). J Wakayama Med Soc 1995;46:213-7.
20. Imai Y, Kawabe T, Takahashi M, Matsumura M, Komatsu Y, Hamada E, et al. A case of primary gastric choriocarcinoma and a review of the Japanese literature. J Gastroenterol 1994;29:6426.

21. Motoyama T, Aizawa K, Fujiwara T, Endoh Y, Watanabe H. Coexistence of choriocarcinoma and hepatoid adenocarcinoma in the stomach. Pathol Int 1994;44:716-21.

22. Fujimoto K, Tanaka H, Takeda H. A case of primary gastric choriocarcinoma with adenocarcinoma (in Japanese with English abstract). J Jpn Soc Clin Surg 1994;55:1480-3.

23. Ogura Y, Ko K, Higuchi K, Katayama M, Shimizu N, Yamaguchi $\mathrm{Y}$, et al. A case of advanced gastric cancer associated with primary ciliary cancer and adenocarcinoma (in Japanese with English abstract). J Jpn Soc Clin Surg 1993;54:2592-6.

24. Saito Y, Saito T, Kimura K, et al. Case report of a rapidly progressing choriocarcinoma (in Japanese with English abstract). Shokaki Naishikyo (Endoscopia Digestiva) 1992;4:1535-40.

25. Fukata S, Nimura Y, Kamiya J, Kondo S, Yasui A, Nagino M. A case of primary gastric choriocarcinoma with interesting histological findings (in Japanese). Jpn J Gastroenterol 1991;88:2877-82.

26. Masuda R, Isoyama T, Bandou T, Toyoshima H, Takemura T. A primary choriocarcinoma of the stomach with a review of 45 cases in Japan (in Japanese). Gan No Rinsho (Jpn J Cancer Clinics) 1990;36:1025-30.

27. Krulewski T, Cohen LB. Choriocarcinoma of the stomach: pathogenesis and clinical characteristics. Am J Gastroenterol 1988;83:1172-5.

28. Okada K, Yokoyama S, Mochizuki Y, Moriuchi A, Yamashita H, Yasunaga A, et al. An autopsy case of primary gastric choriocarcinoma. Jpn J Clin Oncol 1987;17:263-73.

29. Tanaka A, Henmi K, Nitta N, Okanoue T, Sato I, Yamamoto Y, et al. Report of three cases of specific type cancer of the upper gastrointestinal tract: adenosquamous cell carcinoma of the esophagus, choriocarcinoma of the stomach (in Japanese with English abstract). Arch Jpn Chir 1985;54:39-47.

30. Fukuda Y, Sakurai M, Matsuura N. Primary gastric choriocarcinoma. Report of an autopsy case with immunohistochemical study. Acta Pathol Jpn 1985;35:655-66.

31. Hayashi K, Motoi S, Tsutsumi K, Endo T. A case of gastric malignant chorioepithelioma of the male. Gan No Rinsho (Jpn J Cancer Clinics) 1981;27:1654-60.

32. Sugiyama Y, Chiba M, Ino M, Kikuchi A, Yokouchi M. Coexistence of chorioepithelioma and carcinoma in the stomach of a man. Case report and review of the literature in the male subject (in Japanese with English abstract). Stomach and Intestine 1977;12:371-6.

33. Regan JF, Cremin JH. Choriocarcinoma of the stomach. Am J Surg 1960;100:224-33.

34. Sobin LH, Wittekind Ch, editors. UICC TNM classification of malignant tumours. 5th ed. New York: John Wiley \& Sons; 1997.

35. Davidsohn C. Chorion-epitheliom and magenkrebs, eine seltene verschmelzung zweizer bosartiger geschwulste. Charite Annal 1905;29:426-36.

36. Pick L. Uber die chorionepitheliomahnliche metastasierende Form des Magencarcinoma. Klin Wochenschr 1926;5:1728-9.

37. Liu AY, Chang WY, Ng EK, Zhang X, Li BC, Chow JH, et al. Gastric choriocarcinoma shows characteristics of adenocarcinoma and gestational choriocarcinoma: a comparative genomic hybridizatioin and fluorescence in situ hybridization study. 2001;10:161-5. 